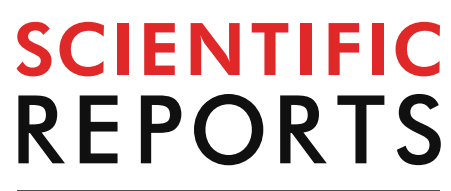

natureresearch

Check for updates

\title{
Parameters of geochemical effect equation for lanthanides and their geochemical significance for a series of metamorphic coals
}

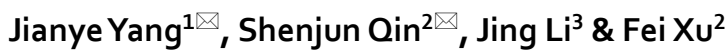

The "geochemical effect of lanthanides" is a new concept proposed by the authors during the past decade. This concept reflects lanthanide shrinkage in elemental geochemistry, and it is statistically quantifiable. However, the geological significance of the various parameters of the equations obtained following quantization is not entirely clear. Cooperation and discussions from scholars in related research fields of rare earth elements in geology are required. In the present paper, from the perspective of coal geochemistry, the metamorphic coal seam of $\mathrm{C2}$ series in Fengfeng Mine of Handan Coalfield in Hebei Province, China was used as an example. The geochemical significance of parameters in geochemical effect regression equation for lanthanides was evaluated, and two new formulas (regression equations) that characterized the geochemical behaviors of lanthanides were proposed. On this basis, concepts related to the geochemical effect of lanthanides, such as "individual parameters", "parameters in common", "two-sided parameters", and the "deviation value" of lanthanides, were proposed. In this study, it was proved that the goodness of fit for all types of function regression equations for lanthanides and the radii of their trivalent ions, and the "deviation value" of lanthanides, were all "individual parameters" that could indicate the postmodified geological environment of $C 2$ coal seam, such as the influence from magmatic-hydrothermal fluids. A covariant figure was constructed according to these individual parameters and other indexes, and the $\mathrm{C} 2$ coal seam in Handan was effectively divided into two different metamorphic series of $A$ ( $C 2$ coal seam uninfluenced or slightly influenced by magmatic-hydrothermal fluids) and B ( $C 2$ coal seam strongly influenced and evidently changed by magmatic-hydrothermal fluids). Consequently, the scientific significance of all the parameters for lanthanides in an identifying series of metamorphic coals within the geochemical effect regression equation was further clarified.

The so-called "geochemical effect of lanthanides" phenomenon was established by the authors 10 years ago. This effect is a geochemical reflection of lanthanide contraction in the periodic table of elements, i.e., any quantifiable geochemical behaviors of lanthanides (for example: the normalized values of chondrite for lanthanides as well as the parameters characterizing the migration, distribution, and occurrence modes of lanthanides in geological bodies can all be considered as the results of quantifiable geochemical behaviors) usually have a strong linear relationship with certain atomic structural parameters (such as the radii of their trivalent ions) ${ }^{1-8}$. To investigate this relationship, lanthanides can be divided either into two parts (LREE and HREE), or take the 14 elements of lanthanides can be evaluated comprehensively. This relationship is described either by a linear regression function or through other functions, such as quadratic polynomial function, log function, exponential function, or power function. Usually, there are significant differences in the manifestations of the geochemical effect of lanthanides among geological bodies of different genetic types ${ }^{5,6}$. These differences likely result from the bodies' unique geochemical states and processes, and so useful geological information may be acquired from them.

\footnotetext{
${ }^{1}$ College of Material Science and Engineering, Xi'an University of Science and Technology, Xi'an 710054, China. ${ }^{2}$ Key Laboratory for Resource Exploration Research of Hebei Province, Hebei University of Engineering, Handan 056038, China. ${ }^{3}$ College of Resources, China University of Geosciences, Wuhan 430074, China. ${ }^{\square}$ email: yjyxust@163.com; qinsj528@hebeu.edu.cn
} 

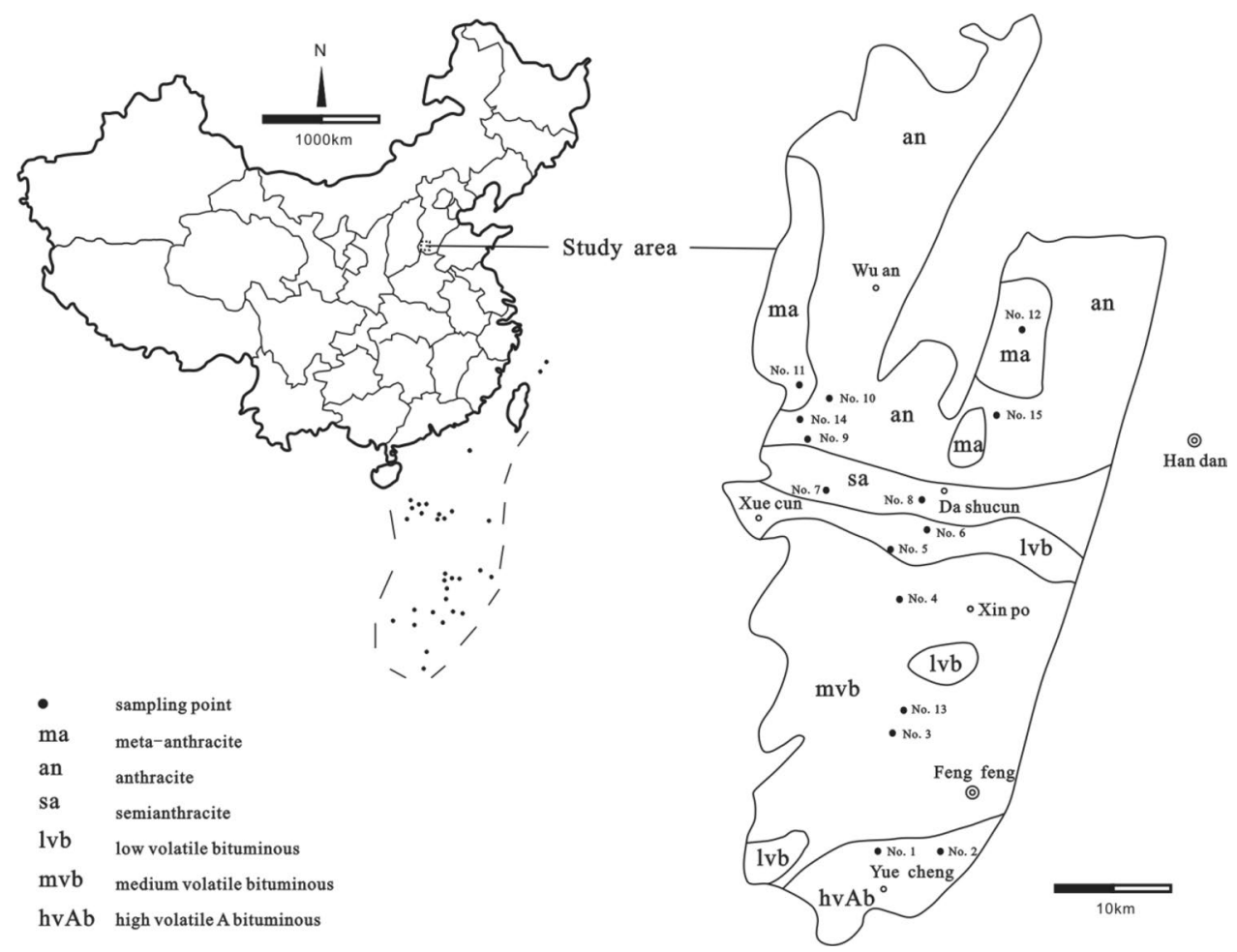

Figure 1. Location of the $\mathrm{C} 2$ coal seam and sampling location in the Fengfeng mine of the Handan Coalfield, Hebei Province (Dai and Ren, $2007^{10}$ ).

Within the currently available literature, there is no corresponding background information about this phenomenon. A few textbooks have mentioned that the complexation potential of the lanthanide elements enhances with an increase in their atomic numbers. However, these publications do not thoroughly probe into the atomic structural parameters of the lanthanide elements, such as the radii of their trivalent ions 9 .

Since the discovery of the geochemical effect of lanthanides, this research topic has received considerable attention from the authors, who have focused on the scientific significance and applications of this effect. In a recent article, we proposed a geochemical effect equation for lanthanides and explored the geochemical significance of certain parameters in all types of function regression equations ${ }^{8}$. However, being limited by the conditions at the time, we were unsuccessful in recognizing the geological significance of goodness of fit, which is a highly essential parameter within these regression equations. Concurrently, the explanation for the scientific significance of certain evaluated parameters was not sufficiently thorough. In this context, we took the late Paleozoic C2 coal seam of Handan Coalfield in Hebei Province of China as an ideal example and further evaluated the geological and geochemical significance of all parameters in the geochemical effect regression equation for lanthanides.

Geological setting and previous research. The Fengfeng Mine of Handan Coalfield (Hebei Province, China) was selected as the study area (Fig. 1), which contains a series of late Paleozoic coal-bearing strata (Fig. 2). Owing to the influence of Yanshanian magmatism on the C2 coal seam of the Shanxi Formation in the Early Permian, a series of thermal metamorphisms occurred almost continuously from south to north in the same coal seam; as a result, the coal gradually changed from low-rank bituminous to high-rank meta-anthracite (Fig. 1). To understand the influence of magmatism and coal's thermal metamorphism on the migration and distribution of elements in coal, systematic sampling and analyses have been conducted on coals with different ranks of metamorphism ( $R_{\max }$ from $0.89 \%$ to $7.41 \%$ ) in the $\mathrm{C} 2$ coal seam. The important parameters, including the concentration of lanthanides are shown in Table 1. Sampling and analysis methods were exhibited in the literature ${ }^{10}$. The previous work in this field has established a useful foundation for our study.

Research ideas and methods applied in this study. After numbering 12 coal samples according to the ranks of the C2 coal seam from low to high as No. 1-No. 12, their lanthanides were normalized with chondrite, and the results of normalization and the radii of their trivalent ions were subjected to a regression analysis with a linear function, quadratic polynomial function, log function, exponential function, and power function. The key obtained parameters are shown in Table 2. On this basis, the relationships between these parameters and other known geochemical parameters were utilized in investigating the geological and geochemical significance of these parameters. 


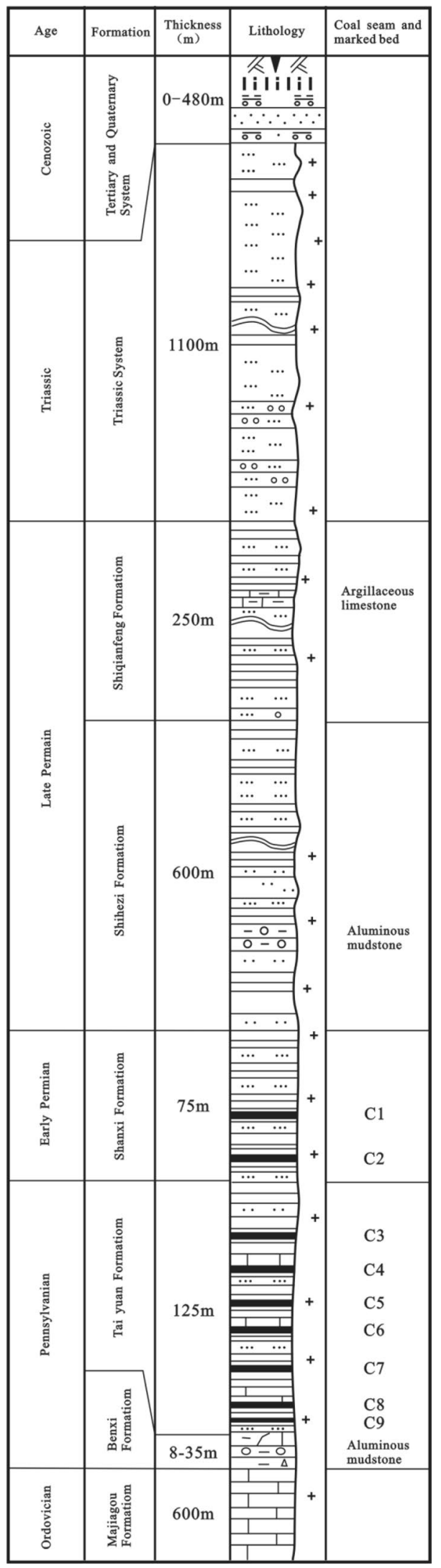

Figure 2. Profile of the sedimentary sequence of coal-bearing strata in the Fengfeng mine of the Handan Coalfield, Hebei Province (Dai and Ren, $2007^{10}$ ). 


\begin{tabular}{|c|c|c|c|c|c|c|c|c|c|c|c|c|c|c|c|c|c|c|c|c|c|c|c|}
\hline $\begin{array}{l}\text { Samples } \\
\text { number }\end{array}$ & $\begin{array}{c}\text { Coal } \\
\text { seam }\end{array}$ & $\begin{array}{l}\text { Coal } \\
\text { rank }\end{array}$ & $R_{\max }$ & La & $\mathrm{Ce}$ & $\operatorname{Pr}$ & $\mathrm{Nd}$ & Sm & Еu & Gd & Tb & Dy & Ho & Er & $\mathrm{Tm}$ & Yb & Lu & $\delta \mathrm{Ce}$ & ઈЕи & LREE & HREE & $\begin{array}{l}\text { LREE/ } \\
\text { HREE }\end{array}$ & ¿REE \\
\hline No. 1 & C2 & hvAb & 0.95 & 17.23 & 33.11 & 3.77 & 14.12 & 2.82 & 0.69 & 2.7 & 0.41 & 2.48 & 0.5 & 1.36 & 0.2 & 1.22 & 0.2 & 0.984 & 0.759 & 71.74 & 9.07 & 7.909 & 80.81 \\
\hline No. 2 & $\mathrm{C} 2$ & hvAb & 0.89 & 17.2 & 33.08 & 3.74 & 14.09 & 2.79 & 0.64 & 2.67 & 0.38 & 2.45 & 0.47 & 1.33 & 0.17 & 1.19 & 0.18 & 0.988 & 0.712 & 71.54 & 8.84 & 8.092 & 80.38 \\
\hline No. 3 & $\mathrm{C} 2$ & $\mathrm{mvb}$ & 0.98 & 12.98 & 23.63 & 2.59 & 9.43 & 1.71 & 0.38 & 1.63 & 0.26 & 1.52 & 0.31 & 0.86 & 0.14 & 0.83 & 0.15 & 0.977 & 0.691 & 50.72 & 5.7 & 8.898 & 56.42 \\
\hline No. 4 & C2 & $\mathrm{mvb}$ & 1.39 & 15.52 & 30.6 & 3.64 & 13.9 & 2.94 & 0.62 & 2.86 & 0.47 & 2.75 & 0.55 & 1.6 & 0.24 & 1.55 & 0.25 & 0.976 & 0.649 & 67.22 & 10.27 & 6.545 & 77.49 \\
\hline No. 5 & $\mathrm{C} 2$ & $\mathrm{lvb}$ & 1.58 & 14.55 & 26.65 & 2.79 & 9.99 & 1.75 & 0.38 & 1.68 & 0.26 & 1.51 & 0.31 & 0.88 & 0.14 & 0.82 & 0.14 & 1.002 & 0.673 & 56.11 & 5.74 & 9.775 & 61.85 \\
\hline No. 6 & C2 & lvb & 1.79 & 17.89 & 32.35 & 3.42 & 12.19 & 2.13 & 0.54 & 2.04 & 0.31 & 1.8 & 0.38 & 1.12 & 0.17 & 1.08 & 0.2 & 0.991 & 0.786 & 68.52 & 7.1 & 9.650 & 75.62 \\
\hline No. 7 & C2 & sa & 2.14 & 15.96 & 29.83 & 3.29 & 11.83 & 2.15 & 0.51 & 2.05 & 0.32 & 1.87 & 0.37 & 1.07 & 0.16 & 1.03 & 0.18 & 0.986 & 0.737 & 63.57 & 7.05 & 9.017 & 70.62 \\
\hline No. 8 & $\mathrm{C} 2$ & sa & 2.25 & 24.37 & 43.54 & 4.36 & 14.66 & 2.59 & 0.55 & 2.56 & 0.39 & 2.27 & 0.45 & 1.3 & 0.19 & 1.18 & 0.2 & 1.012 & 0.648 & 90.07 & 8.54 & 10.54 & 98.61 \\
\hline No. 9 & C2 & an & 4.51 & 13.58 & 26.88 & 3.04 & 11.88 & 2.35 & 0.5 & 2.45 & 0.4 & 2.28 & 0.48 & 1.42 & 0.21 & 1.39 & 0.24 & 1.002 & 0.632 & 58.23 & 8.87 & 6.564 & 67.1 \\
\hline No. 10 & C2 & an & 6.15 & 20.68 & 34.37 & 3.29 & 11.04 & 1.83 & 0.46 & 1.95 & 0.28 & 1.61 & 0.33 & 0.93 & 0.14 & 0.82 & 0.15 & 0.998 & 0.739 & 71.67 & 6.21 & 11.54 & 77.88 \\
\hline No. 11 & C2 & $\mathrm{ma}$ & 6.54 & 19.09 & 39.14 & 4.2 & 14.87 & 2.97 & 0.57 & 2.86 & 0.44 & 2.73 & 0.53 & 1.57 & 0.24 & 1.55 & 0.24 & 1.047 & 0.593 & 80.84 & 10.16 & 7.956 & 91 \\
\hline No. 12 & $\mathrm{C} 2$ & $\mathrm{ma}$ & 7.41 & 13.88 & 26.81 & 2.84 & 10.51 & 1.74 & 0.36 & 1.74 & 0.25 & 1.42 & 0.3 & 0.84 & 0.13 & 0.8 & 0.15 & 1.023 & 0.628 & 56.14 & 5.63 & 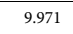 & 61.77 \\
\hline $\begin{array}{l}\text { Chondrite } \\
\text { (Anders et al. } \\
1989 \text { Chon- } \\
\text { drite 10-6) }\end{array}$ & & & & 0.234 & 0.603 & 0.089 & 0.452 & 0.147 & 0.056 & 0.196 & 0.036 & 0.242 & 0.055 & 0.158 & 0.024 & 0.162 & 0.024 & & & & & & \\
\hline $\begin{array}{l}\text { Radius of } \\
\text { lanthanides } \\
\text { trivalent ion }\end{array}$ & & & & 1.061 & 1.03 & 1.01 & 1.03 & 0.96 & 0.95 & 0.94 & 0.92 & 0.91 & 0.89 & 0.88 & 0.87 & 0.86 & 0.85 & & & & & & \\
\hline
\end{tabular}

Table 1. Metamorphism, lanthanide abundance and related parameters of Late Paleozoic C2 coal seam in Fengfeng mine, China (Dai and Ren, $2007^{10}$ ). $h v A b$ high-volatile A bituminous, $m v b$ medium-volatile bituminous, $l v b$ low-volatile bituminous, $s a$ semianthracite, an anthracite, ma meta-anthracite.

\begin{tabular}{|c|c|c|c|c|c|c|c|c|c|c|c|c|c|c|c|c|}
\hline $\begin{array}{l}\text { Samples } \\
\text { number }\end{array}$ & LREE lgf & $\begin{array}{l}\text { HREE } \\
\text { lgf }\end{array}$ & REE lgf & $\begin{array}{l}\text { REE } \\
\text { pgf1 }\end{array}$ & REE egf & REE lgf & $\begin{array}{l}\text { REE } \\
\text { pgf2 }\end{array}$ & $\begin{array}{l}\text { LREE } \\
\text { lrc }\end{array}$ & $\begin{array}{l}\text { REE } \\
\text { lrc1 }\end{array}$ & $\begin{array}{l}\text { REE } \\
\text { prc1 }\end{array}$ & REE erc & $\begin{array}{l}\text { REE } \\
\operatorname{lrc2}\end{array}$ & REE liv & $\begin{array}{l}\text { REE } \\
\text { prc2 }\end{array}$ & EivXv & pev \\
\hline No. 1 & 0.823 & 0.888 & 0.788 & 0.926 & 0.928 & 0.769 & 0.917 & 477.4 & 264.3 & 1,982 & 0.0007 & 247.8 & 38.09 & 30.91 & 10.75 & 10.15 \\
\hline No. 2 & 0.827 & 0.888 & 0.791 & 0.927 & 0.932 & 0.772 & 0.921 & 482.6 & 267.0 & 1,984 & 0.0004 & 250.4 & 37.84 & 30.47 & 11.18 & 10.56 \\
\hline No. 3 & 0.814 & 0.653 & 0.74 & 0.916 & 0.876 & 0.718 & 0.860 & 375.8 & 192.0 & 1,684 & 0.0003 & 179.7 & 26.74 & 20.50 & 10.97 & 10.33 \\
\hline No. 4 & 0.839 & 0.786 & 0.785 & 0.926 & 0.883 & 0.765 & 0.869 & 427.1 & 231.5 & 1,768 & 0.0029 & 217.1 & 35.96 & 30.02 & 9.225 & 8.692 \\
\hline No. 5 & 0.805 & 0.749 & 0.731 & 0.909 & 0.881 & 0.709 & 0.866 & 428.9 & 216.9 & 1,925 & 0.0002 & 203.0 & 29.33 & 21.89 & 11.63 & 10.95 \\
\hline No. 6 & 0.798 & 0.454 & 0.726 & 0.911 & 0.871 & 0.704 & 0.854 & 518.0 & 263.4 & 2,390 & 0.0003 & 246.3 & 35.94 & 26.92 & 11.32 & 10.65 \\
\hline No. 7 & 0.814 & 0.690 & 0.752 & 0.917 & 0.892 & 0.731 & 0.878 & 460.7 & 241.1 & 2,034 & 0.0003 & 225.7 & 33.44 & 25.79 & 11.21 & 10.56 \\
\hline No. 8 & 0.778 & 0.802 & 0.708 & 0.892 & 0.880 & 0.687 & 0.865 & 722.3 & 357.9 & 3,281 & 0.0002 & 334.7 & 47.06 & 33.94 & 12.24 & 11.53 \\
\hline No. 9 & 0.844 & 0.558 & 0.760 & 0.925 & 0.847 & 0.739 & 0.830 & 384.2 & 198.3 & 1,660 & 0.0032 & 185.7 & 30.89 & 25.43 & 8.964 & 8.429 \\
\hline No. 10 & 0.755 & 0.736 & 0.683 & 0.882 & 0.886 & 0.662 & 0.871 & 606.4 & 293.7 & 2,844 & 0.00007 & 274.4 & 37.66 & 26.28 & 12.78 & 12.04 \\
\hline No. 11 & 0.810 & 0.774 & 0.749 & 0.906 & 0.860 & 0.729 & 0.845 & 560.9 & 292.2 & 2,400 & 0.0011 & 273.7 & 42.12 & 33.09 & 10.34 & 9.742 \\
\hline No. 12 & 0.831 & 0.579 & 0.749 & 0.920 & 0.876 & 0.727 & 0.860 & 418.7 & 214.7 & 1,847 & 0.0002 & 201 & 29.04 & 21.73 & 11.76 & 11.07 \\
\hline
\end{tabular}

Table 2. Important parameters obtained by regression of normalized lanthanide chondrite and the radius of their trivalent ion using various functions in the coals from Late Paleozoic C2 coal seam in Fengfeng mine, China. $l g f$ linear goodness of fit, $p g f 1$ polynomial goodness of fit, egf exponential goodness of fit, $\lg f$ $\log$ goodness of fit, $p g f 2$ power goodness of fit, $\operatorname{lrc} 1$ linear regression coefficient, $p r c 1$ polynomial regression coefficient, erc exponential regression coefficient, $\operatorname{lrc} 2 \log$ regression coefficient, liv log intercept values, $p r c 2$ power regression coefficient, EivXv exponential independent variable $\mathrm{X}$ value, pev power exponent value.

\section{Results and discussion}

Correlation of parameters in the regression equation and parameters of REE. We took the relationship of lanthanides normalized with chondrite and the radii of their trivalent ions as an example and confirmed the previous findings. Specifically, the regression coefficients of each function (i.e., slope in the case of linear regression) from this study had significantly positive correlations with $\Sigma$ REE and $\sum L R E E$, and the power exponent of the power function has a significantly linear positive correlation with LREE/HREE ${ }^{8}$. In addition, this study also identified significant positive correlations between the intercept values obtained from log function regression and $\sum$ REE, with a goodness of fit value of above 0.99 (Fig. 3a) and a value of 1 for some coal samples. The regression coefficients of the log function also showed significant positive correlations with the LREE concentration (with a goodness of fit of 0.9228 , Fig. $3 \mathrm{~b}$ ). On this basis, a new regression equation was proposed:

$$
F=k_{1} \sum L R E E \ln r+k_{2} \sum R E E,
$$

where $F$ is one of the geochemical behaviors of lanthanides, $r$ is the radius of trivalent ion for lanthanides, and $k_{1}$ and $k_{2}$ are both proportionality coefficients. In the case of normalization of lanthanides with chondrite (the 

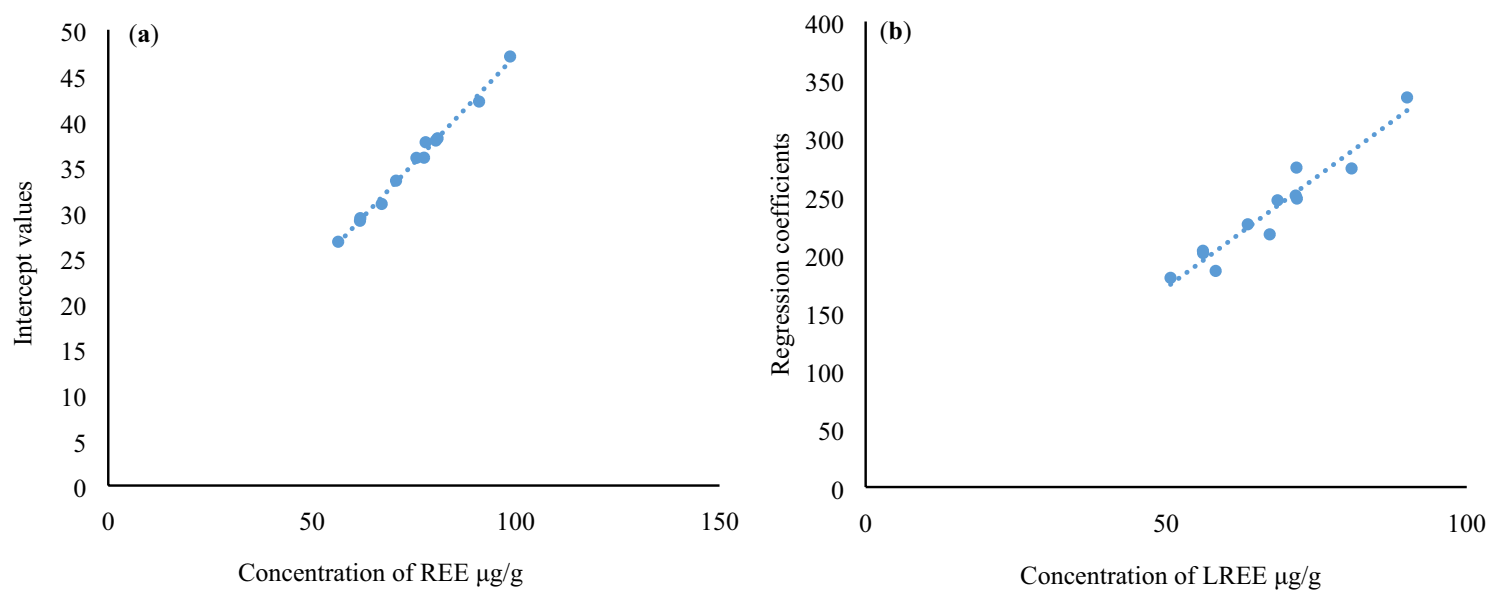

Figure 3. (a) Correlation between the intercept values obtained from log function regression for the geochemical effect of lanthanides in the C2 coal seam in Fengfeng Mine of Handan Coalfield in Hebei Province and the total concentration of REE, and (b) the correlation between the regression coefficients and concentration of LREE. The original data of REE refer to Table 1 (Dai Shifeng, $2007^{10}$ ), the regression coefficients refer to Table 2.

normalization process with chondrite was also taken as a geochemical process of the lanthanides, and more specifically their differentiation results relative to chondrite), the value of $k_{2}$ can be approximated to 1 .

In regression functions, few regression parameters have a correlation with $\Sigma$ HREE. In this study, the regression coefficients of the power function for lanthanides in $\mathrm{C} 2$ coal seam of Handan and the radii of their trivalent ions had a significant positive correlation with $\Sigma$ HREE (with a goodness of fit of 0.7033 ). Therefore, revising the equation as the following, produces a formula that is better than its counterpart in the literature ${ }^{8}\left(F=-k_{1} \sum \mathrm{REE} r^{k 2 f}\right)$.

$$
F=-K\left(k_{0}^{\prime} \sum L R E E+k_{1}^{\prime} \sum H R E E\right) r^{k 2} f,
$$

where $r$ represents the radii of trivalent ions of lanthanides, $f$ is the differentiation degree of light (LREE) and heavy rare earth (HREE) elements, i.e., LREE/HREE, $k_{0}, k_{1}$, and $k_{2}$ are all proportionality coefficients, and $k_{0}^{\prime}$ and $k_{1}^{\prime}$ are proportionality coefficients produced after extracting the common factor $K$.

Three parameter types in the geochemical effect regression equation for lanthanides. Certain parameters listed in the above formulas, including regression coefficients, intercept values, and power exponents in the regression equation, are referred to as "parameters in common" in this paper, as the relationships of these parameters with $\Sigma$ REE, $\Sigma$ LREE, $\Sigma$ HREE, and LREE/HREE are universal. Their geochemical significance conforms to the geochemical effect of lanthanides in coal and fits within geological bodies other than coal, such as the geochemical effect of lanthanides in magmatic rock (to be discussed later). Regardless of whether these samples were obtained from the same coal seam (or cognate magmatic rock, metamorphic rock or sedimentary rock, and so on) or different coal seams (or different sources and different kinds of magmatic rock, metamorphic rock, or sedimentary rock, and so on), the geochemical parameter characteristics of lanthanides (i.e., $\sum$ REE, LREE/HREE, and so on) can always be described with the above parameters. Thus, the rule is "universally applicable". This suggests that any geochemical behaviors or processes of lanthanides are limited by grand heat-tectonic events in geology and are strictly restrained by the internal microstructures of their ions in statistics. Moreover, these behaviors or processes are always closely related to the parameters of lanthanides, such as $\Sigma$ REE, $\Sigma$ LREE, $\Sigma$ HREE, LREE/HREE, and so on. The geochemical behavior of every single lanthanide has a strict functional relationship with the radius of its trivalent ion, the total quantities of $\sum$ REE and $\sum L R E E$, and the differentiation degree of heavy and light rare earth elements. In other words, these are not purely individual behaviors. However, it is entirely possible that the values and \pm of the proportionality coefficients in the above formulas (such as $K, k_{0}^{\prime}, k_{1}^{\prime}, k_{1}, k_{2}$, and so on) might vary with the different geochemical processes experienced by lanthanides, their different occurrence modes, their different geochemical environments, and so forth. Thus, they can be regarded as the "individual parameters" or "state parameters" in the above regression equations. For example, the complexation ability of lanthanides increases constantly with the reduction of the ionic radius. In this process, $k_{1}$ in formula (1) should be negative. In contrast, in the fractional crystallization process of magma, the relationships of the LREE and HREE after normalization with chondrite and the radii of their trivalent ions usually presented a significant double-pitch-up pattern, i.e., the $K$ values of the regression coefficients in these linear relationships should all be positive $e^{6,9}$. The latter research will show that the "deviation value" of lanthanides is also an "individual parameter".

In this study, the linear regression coefficients in the relationship of the LREE after normalization with chondrite and the radius of its trivalent ion (hereinafter called "regression coefficients of geochemical effect equation for chondrite-linear lanthanides") had significant or even highly significant positive correlations with concentration of $\mathrm{Al}, \mathrm{Si}, \mathrm{La}, \mathrm{Ce}$, and $\mathrm{Pr}$ (Table 3, with goodness of fit values of $0.4919,0.5062,0.9838,0.8617$, and 0.5559 , respectively). $\mathrm{Yb} / \mathrm{La}$ implies that the presence of multistage hydrothermal activity may also lead to 


\begin{tabular}{|c|c|c|c|c|c|c|c|c|c|c|c|c|}
\hline Element & No. 1 & No. 2 & No. 3 & No. 4 & No. 5 & No. 6 & No. 7 & No. 8 & No. 9 & No. 10 & No. 11 & \begin{tabular}{|l|} 
No. \\
12 \\
\end{tabular} \\
\hline Ash yield & 18.5 & 16.2 & 19.5 & 16.1 & 18.6 & 20.6 & 22.4 & 19.7 & 23.4 & 26.6 & 30.3 & 22.1 \\
\hline $\mathrm{Al}_{2} \mathrm{O}_{3}$ & 6.49 & 5.24 & 7.21 & 5.53 & 6.85 & 6.86 & 7.21 & 12.57 & 6.93 & 8.22 & 5.48 & 5.47 \\
\hline $\mathrm{SiO}_{2}$ & 13.25 & 11.85 & 15.86 & 11.25 & 13.54 & 15.47 & 14.86 & 21.22 & 15.25 & 18.45 & 14.06 & 12.05 \\
\hline $\mathrm{MgO}$ & 0.26 & 0.15 & 0.13 & 0.44 & 0.28 & 0.44 & 0.68 & 1.52 & 1.22 & 0.98 & 1.38 & 1.41 \\
\hline $\mathrm{CaO}$ & 0.89 & 0.78 & 1.65 & 0.68 & 1.81 & 0.48 & 1.21 & 10.36 & 4.25 & 1.92 & 6.65 & 8.54 \\
\hline $\mathrm{K}_{2} \mathrm{O}$ & 0.27 & 0.28 & 0.05 & 0.46 & 0.05 & 0.26 & 0.18 & 0.10 & 0.18 & 0.28 & 0.05 & 0.25 \\
\hline $\mathrm{Na}_{2} \mathrm{O}$ & 0.09 & 0.11 & 0.43 & 0.19 & 0.16 & 0.08 & 0.09 & 0.07 & 0.10 & 0.05 & 0.23 & 0.35 \\
\hline $\mathrm{TiO}_{2}$ & 0.34 & 0.24 & 0.14 & 0.52 & 0.59 & 0.49 & 0.32 & 0.78 & 0.33 & 0.22 & 0.70 & 0.68 \\
\hline $\mathrm{Fe}_{2} \mathrm{O}_{3}$ & 0.60 & 0.65 & 0.78 & 0.54 & 0.72 & 0.89 & 0.84 & 1.25 & 1.84 & 2.65 & 8.56 & 1.48 \\
\hline $\mathrm{MnO}_{2}$ & 0.09 & 0.03 & 0.02 & 0.02 & 0.01 & 0.10 & 0.06 & 0.17 & 0.15 & 0.10 & 0.17 & 0.20 \\
\hline $\mathrm{P}_{2} \mathrm{O}_{5}$ & 0.03 & 0.03 & 0.03 & 0.41 & 0.02 & 0.02 & 0.51 & 0.83 & 0.16 & 0.22 & 0.76 & 0.49 \\
\hline $\mathrm{Al}$ & 3.435 & 2.774 & 3.816 & 2.927 & 3.626 & 3.631 & 3.816 & 6.6545 & \begin{tabular}{|l|}
3.668 \\
\end{tabular} & 4.3516 & 2.9011 & 2.8958 \\
\hline $\mathrm{Si}$ & 6.188 & 5.534 & 7.407 & 5.254 & 6.323 & 7.224 & 6.94 & 9.91 & 7.122 & 8.616 & 6.566 & 5.627 \\
\hline $\mathrm{Mg}$ & 0.157 & 0.09 & 0.078 & 0.265 & \begin{tabular}{|l|}
0.169 \\
\end{tabular} & 0.265 & 0.41 & 0.917 & 0.736 & 0.591 & 0.832 & 0.85 \\
\hline $\mathrm{Ca}$ & 0.636 & 0.558 & 1.18 & 0.486 & 1.294 & 0.343 & 0.865 & 7.407 & 3.039 & 1.373 & 4.755 & 6.106 \\
\hline $\mathrm{K}$ & 0.224 & 0.232 & 0.042 & 0.382 & 0.042 & 0.216 & 0.149 & 0.083 & \begin{tabular}{|l|l|}
0.149 \\
\end{tabular} & 0.232 & 0.042 & 0.208 \\
\hline $\mathrm{Na}$ & 0.067 & 0.082 & 0.319 & 0.141 & \begin{tabular}{|l|l|}
0.119 \\
\end{tabular} & 0.059 & 0.067 & 0.052 & 0.074 & 0.037 & 0.171 & 0.26 \\
\hline $\mathrm{Ti}$ & 0.204 & \begin{tabular}{|l|l|}
0.144 \\
\end{tabular} & 0.084 & 0.311 & 0.353 & 0.294 & 0.192 & \begin{tabular}{|l|l|}
0.467 \\
\end{tabular} & \begin{tabular}{|l|l|}
0.198 \\
\end{tabular} & 0.132 & 0.419 & 0.407 \\
\hline $\mathrm{Mn}$ & 0.057 & 0.019 & 0.013 & 0.013 & 0.006 & 0.063 & 0.038 & 0.107 & 0.095 & 0.063 & 0.107 & 0.126 \\
\hline $\mathrm{Fe}$ & 0.419 & 0.454 & 0.545 & 0.377 & 0.503 & 0.622 & 0.587 & 0.874 & 1.286 & 1.852 & 5.983 & 1.035 \\
\hline $\mathrm{P}$ & 0.013 & 0.013 & 0.013 & 0.179 & \begin{tabular}{|l|}
0.009 \\
\end{tabular} & 0.009 & 0.222 & 0.362 & \begin{tabular}{|l|l|}
0.07 \\
\end{tabular} & 0.096 & 0.331 & 0.214 \\
\hline As & 2.31 & 1.25 & 0.55 & 3.51 & 1.59 & 0.79 & 2.46 & 12.88 & 7.45 & 42.23 & 48.41 & 18.38 \\
\hline $\mathrm{Ba}$ & 145.2 & 131.3 & 123.6 & 178.5 & \begin{tabular}{|l|}
192.5 \\
\end{tabular} & 144.3 & 184.7 & 178.4 & 254.6 & 115.8 & 89.4 & 150.3 \\
\hline B & 24.5 & 27.8 & 32.4 & 29.8 & 32.4 & 28.7 & 27.6 & 26.9 & 61.5 & 66.9 & 78.6 & 57.5 \\
\hline $\mathrm{Be}$ & 2.11 & 1.67 & 1.22 & 2.34 & 2.55 & 2.57 & 1.74 & 0.65 & 1.80 & 0.88 & 1.52 & 2.20 \\
\hline $\mathrm{Bi}$ & 0.29 & 0.18 & 0.13 & 0.43 & 1.04 & 0.24 & 0.49 & 0.99 & 0.17 & 0.45 & 0.20 & 0.41 \\
\hline $\mathrm{Br}$ & 9.85 & 10.54 & 11.50 & 10.70 & 6.80 & 12.50 & 15.80 & 95.40 & 73.20 & 112.80 & 98.50 & 70.60 \\
\hline $\mathrm{Ce}$ & 33.11 & \begin{tabular}{|l|}
33.08 \\
\end{tabular} & 23.63 & 30.60 & 26.65 & 32.35 & 29.83 & 43.54 & 26.88 & 34.37 & 39.14 & 26.81 \\
\hline $\mathrm{Cl}$ & 96.9 & 100.7 & 114.5 & 87.6 & 124.4 & 214.9 & 563.2 & 756.3 & 869.7 & $1,220.0$ & 720.4 & 685.5 \\
\hline Co & 2.80 & 2.45 & 2.30 & 1.50 & 1.00 & 3.50 & 2.80 & 4.20 & 14.60 & 29.20 & 33.70 & 18.90 \\
\hline $\mathrm{Cr}$ & 18.40 & 10.55 & 19.10 & 9.60 & \begin{tabular}{|l|}
15.80 \\
\end{tabular} & 18.70 & 21.50 & 10.50 & 14.70 & \begin{tabular}{|l|}
13.30 \\
\end{tabular} & 19.10 & 15.40 \\
\hline Cs & 0.12 & 0.22 & 0.85 & 0.14 & \begin{tabular}{|l|}
0.91 \\
\end{tabular} & 0.54 & 0.25 & 0.11 & 0.09 & 0.04 & 0.18 & 0.09 \\
\hline $\mathrm{Cu}$ & 8.54 & 11.58 & 26.50 & 15.40 & 9.87 & 14.60 & 14.70 & 11.20 & 65.40 & 121.50 & 181.40 & 90.80 \\
\hline Dy & 2.48 & 2.45 & 1.52 & 2.75 & 1.51 & 1.80 & 1.87 & 2.27 & 2.28 & 1.61 & 2.73 & 1.42 \\
\hline $\mathrm{Er}$ & 1.36 & 1.33 & 0.86 & 1.60 & \begin{tabular}{|l|} 
\\
\end{tabular} & 1.12 & 1.07 & 1.30 & 1.42 & 0.93 & 1.57 & 0.84 \\
\hline $\mathrm{Eu}$ & 0.69 & \begin{tabular}{|l|l|}
0.64 \\
\end{tabular} & 0.38 & 0.62 & 0.38 & 0.54 & 0.51 & 0.55 & 0.50 & 0.46 & 0.57 & 0.36 \\
\hline $\mathrm{F}$ & 85.9 & 90.7 & 98.5 & 86.4 & 62.2 & 78.2 & 101.4 & 125.2 & 652.8 & 423.5 & $1,212.1$ & 885.6 \\
\hline $\mathrm{Ga}$ & 12.50 & 13.46 & 14.80 & 5.64 & 8.37 & 9.81 & 11.50 & 12.78 & 15.44 & 3.50 & 9.80 & 8.34 \\
\hline $\mathrm{Gd}$ & 2.70 & 2.67 & 1.63 & 2.86 & 1.68 & 2.04 & 2.05 & 2.56 & 2.45 & 1.95 & 2.86 & 1.74 \\
\hline $\mathrm{Hf}$ & 1.56 & 1.52 & 1.23 & 0.88 & 1.56 & 1.08 & 2.24 & 1.30 & 0.86 & 1.11 & 1.21 & 0.98 \\
\hline $\mathrm{Hg}$ & 0.14 & 0.08 & 0.09 & 0.12 & 0.05 & 0.09 & 0.07 & \begin{tabular}{|l|}
0.09 \\
\end{tabular} & 0.55 & 0.59 & 1.64 & 1.32 \\
\hline Ho & 0.50 & \begin{tabular}{|l|}
0.47 \\
\end{tabular} & 0.31 & 0.55 & 0.31 & 0.38 & \begin{tabular}{|l|}
0.37 \\
\end{tabular} & 0.45 & \begin{tabular}{|l|}
0.48 \\
\end{tabular} & 0.33 & 0.53 & \begin{tabular}{|l|}
0.30 \\
\end{tabular} \\
\hline $\mathrm{La}$ & 17.23 & 17.20 & 12.98 & 15.52 & 14.55 & 17.89 & 15.96 & 24.37 & 13.58 & 20.68 & 19.09 & 13.88 \\
\hline $\mathrm{Lu}$ & 0.20 & 0.18 & 0.15 & 0.25 & 0.14 & 0.20 & 0.18 & 0.20 & 0.24 & 0.15 & 0.24 & 0.15 \\
\hline Mo & 3.41 & 2.89 & 3.50 & 1.36 & 4.30 & 2.20 & 2.42 & 2.90 & 2.88 & 2.41 & 2.11 & 1.25 \\
\hline $\mathrm{Nb}$ & 18.54 & 18.51 & 17.65 & 5.98 & 12.65 & 8.74 & 14.56 & 10.25 & 9.62 & 15.89 & 14.75 & 20.34 \\
\hline $\mathrm{Nd}$ & 14.12 & 14.09 & 9.43 & 13.90 & 9.99 & 12.19 & 11.83 & 14.66 & 11.88 & 11.04 & 14.87 & 10.51 \\
\hline $\mathrm{Ni}$ & 3.15 & 2.78 & 1.40 & 2.32 & 7.75 & 5.40 & 6.63 & 21.66 & 20.77 & 56.89 & 74.59 & 28.65 \\
\hline $\mathrm{Pb}$ & 25.64 & 22.12 & 21.53 & 8.59 & 21.28 & 15.96 & 13.51 & \begin{tabular}{|l|}
18.29 \\
\end{tabular} & 25.44 & 70.24 & 86.58 & 57.85 \\
\hline $\mathrm{Pr}$ & 3.77 & 3.74 & 2.59 & 3.64 & 2.79 & 3.42 & 3.29 & 4.36 & 3.04 & 3.29 & 4.20 & 2.84 \\
\hline $\mathrm{Rb}$ & 1.54 & 1.51 & 1.89 & 1.11 & 1.04 & 1.28 & 2.15 & 1.54 & 2.66 & 24.50 & 18.90 & 8.08 \\
\hline $\mathrm{Sb}$ & 6.42 & 6.33 & 8.95 & 5.48 & 3.55 & 2.54 & 3.60 & 1.11 & \begin{tabular}{|l|l|}
0.18 \\
\end{tabular} & 0.76 & 0.89 & \begin{tabular}{|l|l|}
0.47 \\
\end{tabular} \\
\hline $\mathrm{Sc}$ & 5.58 & 5.21 & 5.22 & 6.45 & 6.32 & 6.85 & 3.21 & 3.96 & \begin{tabular}{|l|l|}
3.47 \\
\end{tabular} & 4.14 & 3.12 & 4.15 \\
\hline $\mathrm{Se}$ & 3.58 & 3.44 & 2.12 & 1.25 & 2.56 & 2.76 & 1.91 & 1.93 & 1.05 & 0.94 & 11.85 & 0.68 \\
\hline $\mathrm{Sm}$ & 2.82 & 2.79 & 1.71 & 2.94 & 1.75 & 2.13 & 2.15 & 2.59 & 2.35 & 1.83 & 2.97 & 1.74 \\
\hline Sn & 7.85 & 8.95 & 11.23 & 8.45 & 10.68 & 12.04 & 8.37 & 11.21 & 6.34 & 8.67 & 13.09 & 6.52 \\
\hline
\end{tabular}




\begin{tabular}{|c|c|c|c|c|c|c|c|c|c|c|c|c|}
\hline Element & No. 1 & No. 2 & No. 3 & No. 4 & No. 5 & No. 6 & No. 7 & No. 8 & No. 9 & No. 10 & No. 11 & $\begin{array}{l}\text { No. } \\
12\end{array}$ \\
\hline $\mathrm{Sr}$ & \begin{tabular}{|l|}
187.5 \\
\end{tabular} & 100.5 & 199.3 & 168.0 & 288.4 & \begin{tabular}{|l|}
197.1 \\
\end{tabular} & 236.1 & 220.5 & 589.5 & $1,024.5$ & 1732.4 & $2,422.0$ \\
\hline $\mathrm{Ta}$ & \begin{tabular}{|l|}
0.32 \\
\end{tabular} & 0.28 & 0.26 & 0.15 & 0.83 & 0.54 & 0.15 & 0.32 & 0.11 & 0.20 & 0.52 & 0.23 \\
\hline $\mathrm{Tb}$ & 0.41 & 0.38 & 0.26 & 0.47 & 0.26 & 0.31 & 0.32 & 0.39 & 0.40 & 0.28 & 0.44 & 0.25 \\
\hline Th & 9.70 & 10.20 & 11.66 & 3.65 & 10.25 & 18.40 & 3.42 & 10.07 & 3.10 & 8.66 & 6.70 & 6.71 \\
\hline $\mathrm{Tm}$ & 0.20 & 0.17 & 0.14 & 0.24 & 0.14 & 0.17 & 0.16 & 0.19 & 0.21 & 0.14 & 0.24 & 0.13 \\
\hline $\mathrm{U}$ & 1.54 & 1.25 & 0.75 & 1.21 & 1.25 & 2.38 & 1.85 & 8.50 & 25.51 & 32.48 & 24.32 & 21.59 \\
\hline $\mathrm{V}$ & 55.56 & 54.88 & 93.65 & 52.87 & 65.82 & 54.09 & 20.75 & 28.54 & 18.49 & 16.58 & 15.44 & 22.36 \\
\hline $\mathrm{W}$ & 1.57 & 1.04 & 1.94 & 0.89 & 1.15 & 2.22 & 0.59 & 1.76 & 2.40 & 2.36 & 2.41 & 2.54 \\
\hline $\mathrm{Y}$ & 12.53 & \begin{tabular}{|l|}
12.48 \\
\end{tabular} & 14.34 & 9.96 & 12.66 & 11.22 & 7.85 & 7.40 & 8.00 & 5.66 & 15.27 & 6.89 \\
\hline $\mathrm{Yb}$ & 1.22 & 1.19 & 0.83 & 1.55 & 0.82 & 1.08 & 1.03 & 1.18 & 1.39 & 0.82 & 1.55 & 0.80 \\
\hline $\mathrm{Zn}$ & 25.63 & 32.62 & 35.21 & 45.71 & 35.42 & \begin{tabular}{|l|}
17.89 \\
\end{tabular} & 34.57 & 138.20 & 88.45 & 70.62 & 121.40 & 150.50 \\
\hline $\mathrm{Zr}$ & \begin{tabular}{|l|}
305.8 \\
\end{tabular} & 251.6 & 154.8 & 265.4 & 302.5 & 127.2 & 170.0 & 75.4 & 105.8 & \begin{tabular}{|l|l|}
92.8 \\
\end{tabular} & 131.0 & 112.4 \\
\hline $\mathrm{Th} / \mathrm{U}$ & 6.298 & 8.16 & 15.54 & 3.016 & 8.2 & 7.731 & 1.848 & 1.1847 & 0.121 & 0.2666 & 0.2754 & 0.3107 \\
\hline $\mathrm{Sr} / \mathrm{Ba}$ & 1.291 & 0.765 & 1.612 & 0.941 & 1.498 & 1.365 & 1.278 & 12.359 & 2.315 & \begin{tabular}{|l|l|}
8.8471 \\
\end{tabular} & 19.378 & 16.114 \\
\hline $\mathrm{Th} / \mathrm{Co}$ & 3.464 & 4.163 & 5.069 & 2.433 & 10.25 & 5.257 & 1.221 & 2.3976 & 0.212 & 0.2965 & 0.1988 & 0.3550 \\
\hline $\mathrm{Zr} / \mathrm{Hf}$ & \begin{tabular}{|l|}
196.0 \\
\end{tabular} & 165.5 & \begin{tabular}{|l|}
125.8 \\
\end{tabular} & 301.5 & \begin{tabular}{|l|l|}
193.9 \\
\end{tabular} & 117.7 & \begin{tabular}{|l|l|}
75.89 \\
\end{tabular} & 58 & 123.0 & 83.603 & 108.26 & 114.69 \\
\hline $\mathrm{Zr} / \mathrm{Nb}$ & 16.49 & 13.59 & \begin{tabular}{|l|l|}
8.770 \\
\end{tabular} & 44.38 & 23.91 & 14.55 & 11.67 & 7.3560 & 10.99 & 5.8401 & 8.8813 & 5.5260 \\
\hline $\mathrm{Yb} / \mathrm{La}$ & 0.070 & \begin{tabular}{|l|}
0.069 \\
\end{tabular} & 0.063 & 0.099 & \begin{tabular}{|l|}
0.056 \\
\end{tabular} & 0.060 & 0.064 & \begin{tabular}{|l|l|}
0.0484 \\
\end{tabular} & 0.102 & \begin{tabular}{|l|l|}
0.0396 \\
\end{tabular} & 0.0811 & 0.0576 \\
\hline $\mathrm{Nb} / \mathrm{Ta}$ & 57.93 & 66.10 & 67.88 & 39.86 & 15.24 & 16.18 & 97.06 & 32.031 & 87.45 & 79.45 & 28.365 & 88.434 \\
\hline$\left(\mathrm{SiO}+\mathrm{Al}_{2} \mathrm{O}_{3}\right) /\left(\mathrm{Fe}_{2} \mathrm{O}_{3}+\mathrm{CaO}+\mathrm{MgO}\right)$ & 11.28 & 10.81 & 9.012 & 10.10 & 7.256 & 12.34 & 8.084 & 2.573 & 3.034 & 4.805 & 1.1779 & 1.5328 \\
\hline
\end{tabular}

Table 3. Ash yield (\%, db), major and minor (wt $\%, d b)$, and trace elements $(\mu \mathrm{g} / \mathrm{g}, \mathrm{db})$ concentrations in the coals from the Fengfeng-Handan Coalfield (Dai and Ren, 2007 ${ }^{10}$ ) and related ratios.
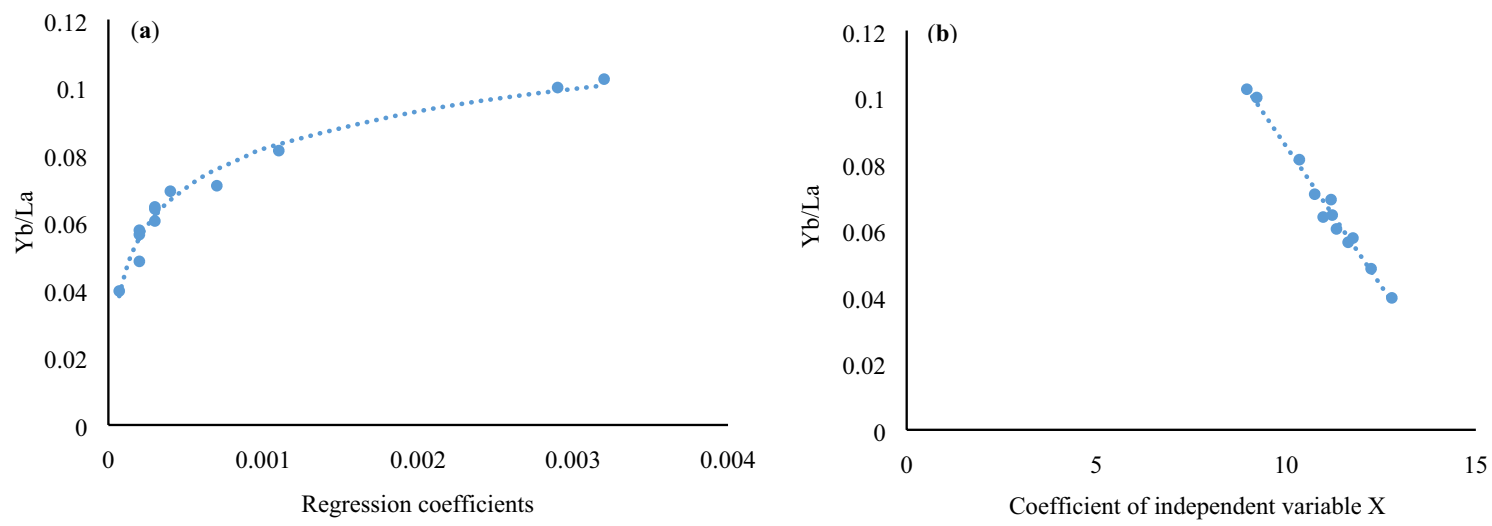

Figure 4. (a) Correlation between regression coefficients in the exponential function of geochemical effect for chondrite-lanthanides and $\mathrm{Yb} / \mathrm{La}$, and $(\mathbf{b})$ the correlation between the coefficient of independent variable $\mathrm{X}$ (i.e., the coefficient of the radius of trivalent ion for lanthanides) and $\mathrm{Yb} / \mathrm{La}$ in the $\mathrm{C} 2$ coal seam. The original data of REE refer to Table 1 (Dai Shifeng, $2007^{10}$ ), the regression coefficients refer to Table 2.

the reallocation of trace elements, including rare earth element of coal-bearing rocks between coal seams and partings. Compared to partings, the high elemental ratios in coal seams ( $\mathrm{Yb} / \mathrm{La}, \mathrm{Nb} / \mathrm{Ta}$, and $\mathrm{Zr} / \mathrm{Hf}$ ) are mainly caused by the re-precipitation of these elements (such as $\mathrm{Yb}, \mathrm{Nb}$, and $\mathrm{Zr}$ ) in coal seams. In partings, these elements $(\mathrm{Yb}, \mathrm{Nb}$, and $\mathrm{Zr}$ ) are more active in the leaching process and are easily leached, adsorbed by the underlying organic matter, and then precipitated in the underlying coal seam ${ }^{11}$. In this study, the regression coefficients in the exponential function of REE have a strong logarithmic relationship with $\mathrm{Yb} / \mathrm{La}$ (Fig. 4a), whereas the coefficient of independent variable $\mathrm{X}$ in the exponential function shows a significant negative correlation with $\mathrm{Yb} /$ La (Fig. 4b). The power exponent obtained from the power function regression presents a similar relationship as shown in Fig. 4b. In addition, it indicates that the "parameters in common" such as certain functional regression coefficients, the coefficient of independent variable $\mathrm{X}$ (note that $\mathrm{X}$ refers to the radius of trivalent ions of lanthanides, which is regarded as a variable according to the regression formula) in the exponential function and power exponent of the geochemical effect of lanthanides, can also reflect geochemical processes under certain conditions; they also display certain characteristics of "state parameters". This is because the ratios of certain elements inside lanthanides themselves have an environmental significance. Therefore, parameters such as the regression coefficients of exponential function for REE share the characteristics of both "parameters in common" and "individual parameters", and these kinds of parameters can thus be called "two-sided parameters". 
The goodness of fit in the above regression equation, which is also an "individual parameter", likely depends upon the sources, geological origin, geological environment, geochemical process, occurrence mode, and other factors related to lanthanides. For example, the goodness of fit of a geochemical effect equation for chondritelinear lanthanides of REE in the C2 coal seam shows a negative correlation with its LREE/HREE (with a goodness of fit of 0.7191). However, in other cases, this relationship may not hold true; one such instance was for the 616 basalt samples obtained from a sea bed ${ }^{12}$ (the detailed description is giving in another paper). This relationship cannot be established if lanthanides are normalized with a depleted mantle or enriched mantle, which represents a different geochemical process. However, in the case of No. 8 coal seam of Taiyuan Formation in Xishan of Taiyuan, Shanxi, China in the literature ${ }^{13}$, there is indeed such a relationship, but it is positive. Regardless of whether the 12 coal samples in C2 coal seam of Handan, or the five samples in No. 8 coal seam in Xishan of Taiyuan, Shanxi in the literature are used ${ }^{13}$, all originate from the same coal seam of different metamorphic degrees. This likely implies that the linear goodness of fit is closely related to the differentiation degree of heavy and light rare earth elements only when the lanthanides are from same source and have undergone different evolutionary or metamorphic phases.

This study also found that the goodness of fit of the geochemical effect equation for chondrite-linear lanthanides of LREE also showed negative correlations with the concentrations of $\mathrm{Al}$, Si, and La (with goodness of fit values of $0.4098,0.5963$, and 0.5328 , respectively); that of REE presented similar correlations with the concentrations of $\mathrm{Al}, \mathrm{Si}$, and $\mathrm{La}$ (with goodness of fit values of $0.4084,0.634$, and 0.5328 , respectively) and was positively correlated with the concentration of $\mathrm{Zr}$ (with a goodness of fit of 0.4147 , which can reach 0.6858 after removing sample No. 5). The goodness of fit of the geochemical effect equation for chondrite-quadratic polynomial lanthanides of REE also showed negative correlations with the concentrations of $\mathrm{Al}, \mathrm{Si}$, and La (with goodness of fit values of $0.4296,0.6369$, and 0.5087 , respectively), and exhibited a positive correlation with the concentration of $U$ when the power function was used for fitting (with a goodness of fit of 0.6876 ). In general, in many cases, the goodness of fit of function regression usually shows a positive or negative correlation with several elements of lanthanides. This suggests that, in this example, some geochemical states (geochemical processes, occurrence modes, or origin evolution types) of lanthanides are related to the activity rules of some lanthanide elements as well as those of non-lanthanide elements especially $\mathrm{Al}$ and $\mathrm{Si}$.

"Deviation value" of lanthanides and its geochemical significance. Both previous studies and this present study indicate that, in some cases, geochemical behaviors of lanthanides in certain geological bodies should be more thoroughly described using a linear geochemical effect equation for lanthanides. In other cases, non-linear functions such as the log function, exponential function, power function, and quadratic polynomials are more appropriate (namely, the goodness of fit of the regression function is higher). At present, it is still difficult to offer a detailed and accurate explanation on this phenomenon. However, we believe that it might have been caused by different "geological or geochemical states". In theory, the higher the goodness of fit for a functional relationship of the geochemical effect of lanthanides, the more singular the geochemical process, or "geological or geochemical states" such as source, origin, occurrence mode of the corresponding lanthanides. Certainly, in this study, it is only a scientific speculation or inference. Regarding the specific correspondence between the functional regression relationship and the geochemical state of lanthanides, studies and statistical analysis are still needed for further clarification. Based on the above speculation and inference and taking the geochemical effect equation for chondrite-linear lanthanides as an example, the investigation was conducted in two parts, i.e., LREE and HREE. The most ideal circumstance for the geochemical processes or occurrence modes characterized is a goodness of fit of 1 . In general, this goodness of fit cannot be 1 , because the geochemical behaviors or states of lanthanides, regardless of their distribution, migration process, or occurrence modes, are not purely singular. Therefore, the geochemical behavioral parameters of some lanthanides obtained from a regression formula with a goodness of fit 1 are only the "ideal value". In most circumstances, the actual values of parameters for some geochemical behaviors of lanthanides do not match ideal values. This "deviation value" can be obtained from the difference between the parameter value obtained from the actual goodness of fit and the ideal value obtained by assuming the goodness of fit of 1 . Table 4 shows the "deviation values" calculated from the geochemical effect equation for chondrite-linear lanthanides in 12 samples of the C2 coal seam in Handan. Tables 1 and 4 show that the deviation values of some elements for LREE are related to the anomaly of Ce. For example, the deviation value of Ce shows a negative correlation with $\delta \mathrm{Ce}$ (goodness of fit $=0.6327$ ), and positive correlations with $\Sigma$ REE and LREE (goodness of fit $=0.6571$ and 0.6724 , respectively). The same is true for the deviation value of $S m$ (the goodness of fit values for $\Sigma R E E$ and $\Sigma L R E E=0.7915$ and 0.737 , respectively), which also has a positive correlation with $\Sigma$ HREE (goodness of fit $=0.5898$ ). The deviation value of Ho shows a negative correlation with $\Sigma$ HREE (goodness of fit $\mathrm{b}=0.44$ ), while the deviation value of Yb exhibits a positive correlation with it (the goodness of fit being 0.4909). Thus, the deviation values of some elements for LREE can reflect their geological environments (such as the oxidation-reduction environments) and that the magnitudes of such deviation values are restrained overall by $\Sigma$ REE, $\Sigma$ LREE, or even $\Sigma$ HREE. The deviation values of La and Eu also show positive correlations with LREE/HREE (goodness of fit $=0.614$ and 0.8127 , respectively), whereas those of Pr and Nd show negative correlations with LREE/HREE (goodness of fit $=0.7703$ and 0.4152 , respectively). This suggests that the differentiation degree of heavy and light rare earth is also one of the reasons causing the "deviation" of lanthanides.

In general, the ratios of many elements can indicate sedimentary environments and geological origins in coal geology. For instance, a smaller ratio of $\mathrm{Th} / \mathrm{U}$ in coal generally reflects a stronger hydrothermal influence on a coal seam ${ }^{14}$. High ratios of $\mathrm{Yb} / \mathrm{La}, \mathrm{Nb} / \mathrm{Ta}$, and $\mathrm{Zr} / \mathrm{Hf}$ are mainly caused by the re-precipitation of $\mathrm{Yb}, \mathrm{Nb}$ and $\mathrm{Zr}$ in the coal seam. In partings, these elements are active in the leaching process and can be easily leached, adsorbed by the underlying organic matter, and precipitated in the underlying coal seam ${ }^{11}$. The ratio of $\mathrm{Nb} / \mathrm{Ta}$ 


\begin{tabular}{|c|c|c|c|c|c|c|c|c|c|c|c|c|c|c|c|c|c|c|}
\hline $\begin{array}{l}\text { Samples } \\
\text { number }\end{array}$ & $\begin{array}{l}\mathrm{La} \\
\text { deviation } \\
\text { value }\end{array}$ & $\begin{array}{l}\mathrm{Ce} \\
\text { deviation } \\
\text { value }\end{array}$ & $\begin{array}{l}\mathrm{Pr} \\
\text { deviation } \\
\text { value }\end{array}$ & $\begin{array}{l}\mathrm{Nd} \\
\text { deviation } \\
\text { value }\end{array}$ & $\begin{array}{l}\text { Sm } \\
\text { deviation } \\
\text { value }\end{array}$ & $\begin{array}{l}\text { Eu } \\
\text { deviation } \\
\text { value }\end{array}$ & $\begin{array}{l}\text { Gd } \\
\text { deviation } \\
\text { value }\end{array}$ & $\begin{array}{l}\text { Tb } \\
\text { deviation } \\
\text { value }\end{array}$ & $\begin{array}{l}\text { Dy } \\
\text { deviation } \\
\text { value }\end{array}$ & $\begin{array}{l}\text { Ho } \\
\text { deviation } \\
\text { value }\end{array}$ & $\begin{array}{l}\text { Er } \\
\text { deviation } \\
\text { value }\end{array}$ & $\begin{array}{l}\text { Tm } \\
\text { deviation } \\
\text { value }\end{array}$ & $\begin{array}{l}\text { Yb } \\
\text { deviation } \\
\text { value }\end{array}$ & $\begin{array}{l}\text { Lu } \\
\text { deviation } \\
\text { value }\end{array}$ & $\begin{array}{l}\text { LREE } \\
\text { Average } \\
\text { deviation } \\
\text { degree }\end{array}$ & $\begin{array}{l}\text { HREE } \\
\text { Average } \\
\text { deviation } \\
\text { degree }\end{array}$ & $\begin{array}{l}\text { Deviation of } \\
\text { (LREE- } \\
\text { HREE)/2 }\end{array}$ & $\begin{array}{l}\text { Deviation } \\
\text { of }(\mathbf{L} / \mathbf{L u})\end{array}$ \\
\hline No. 1 & 9.09586 & 5.36058 & 2.32200 & -18.318 & 3.03063 & 0.95142 & 1.01156 & -0.1784 & -0.6304 & -0.6073 & -0.4169 & -0.0869 & -0.2194 & 1.12770 & 4.56909 & 0.2197 & 2.174660839 & 8.06583 \\
\hline No. 2 & 8.53278 & 5.05104 & 1.83870 & -18.644 & 2.96308 & 0.25157 & 1.14585 & -0.6290 & -0.3337 & -0.6376 & -0.0519 & -0.7284 & 0.23869 & 0.99185 & 4.52959 & 0.2342 & 2.14765836 & 8.60283 \\
\hline No. 3 & 7.81962 & 3.33980 & 0.75026 & -14.990 & 2.09754 & 1.01671 & 0.71078 & 0.12565 & -0.5023 & -0.6464 & -0.5381 & 0.10644 & -0.2993 & 1.03743 & 3.80163 & 0.2104 & 1.795578894 & 7.53742 \\
\hline No. 4 & 6.40838 & 4.25374 & 2.92107 & -15.750 & 3.41400 & -1.2290 & 0.93858 & 0.35569 & -0.7527 & -1.1747 & -0.4892 & -0.1327 & -0.0032 & 1.25476 & 3.69317 & 0.3036 & 1.694744708 & 5.10723 \\
\hline No. 5 & 9.04930 & 4.53313 & 0.24383 & -17.565 & 2.27386 & 1.45221 & 0.77040 & 0.01605 & -0.6106 & -0.6283 & -0.3516 & 0.20959 & -0.2151 & 0.81416 & 4.43582 & 0.1803 & 2.127756235 & 11.1148 \\
\hline No. 6 & 11.6133 & 5.07883 & 0.19323 & -21.606 & 2.19234 & 2.53585 & 1.26083 & -0.0351 & -0.8882 & -0.9298 & -0.4456 & -0.1990 & -0.3074 & 1.54705 & 5.53665 & 0.3096 & 2.613522082 & 7.50673 \\
\hline No. 7 & 9.00717 & 4.74101 & 1.42750 & -18.562 & 2.15510 & 1.25364 & 0.97360 & 0.10854 & -0.6285 & -0.9320 & -0.4795 & -0.2283 & -0.1280 & 1.31425 & 4.59494 & 0.2807 & 2.157080751 & 6.85343 \\
\hline No. 8 & 17.2419 & 7.98149 & -0.8196 & -31.795 & 3.97067 & 3.40842 & 1.17516 & -0.0007 & -0.8406 & -0.9986 & -0.3601 & -0.1393 & -0.1782 & 1.34145 & 8.17286 & 0.2925 & 3.9401751 & 12.8531 \\
\hline No. 9 & 5.76428 & 4.37603 & 1.61686 & -13.926 & 2.68392 & -0.5209 & 1.09847 & 0.32344 & -0.9677 & -1.0614 & -0.4243 & -0.3493 & -0.1393 & 1.51709 & 3.28177 & 0.3223 & 1.479728561 & 3.79956 \\
\hline No. 10 & 17.4178 & 5.08534 & -2.8398 & -27.490 & 2.99931 & 4.83778 & 1.17223 & -0.1873 & -0.8443 & -0.6972 & -0.3570 & -0.0018 & -0.3180 & 1.23138 & 7.48478 & 0.2594 & 3.61265925 & 14.1448 \\
\hline No. 11 & 8.180 & 9.1190 & 2.5886 & -22.89 & 3.6879 & -0.714 & 1.2321 & -0.2009 & -0.5772 & -1.3003 & -0.4558 & 0.0775 & 0.1951 & 1.0297 & 5.33635 & 0.3165 & 2.509893779 & 7.94425 \\
\hline No. 12 & 6.96 & 5.255 & 1.0572 & -15.9 & 1.946 & 0.733 & 1.2053 & -0.136 & -0.862 & -0.696 & -0.494 & -0.098 & -0.236 & 1.3235 & 3.82132 & 0.27323 & 1.77404595 & 5.26494 \\
\hline
\end{tabular}

Table 4. "Deviation value" of lanthanide elements and related parameters in the coals from Late Paleozoic C2 coal seam in Fengfeng mine, China $(\mu \mathrm{g} / \mathrm{g})$.

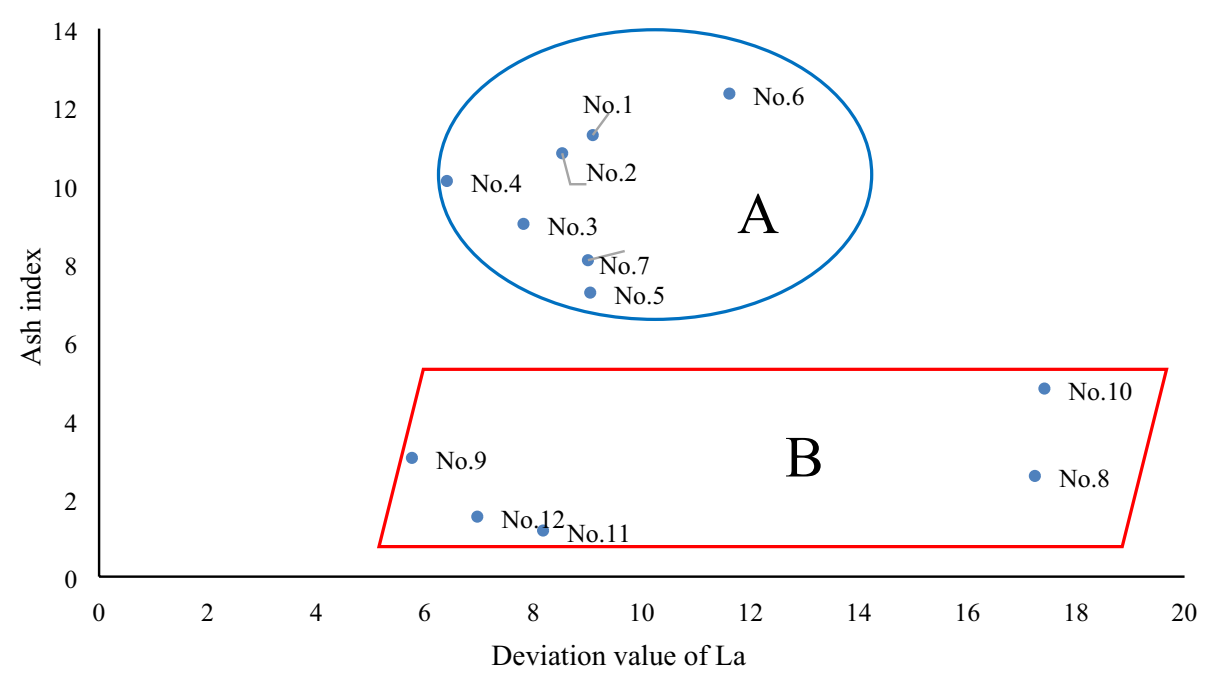

Figure 5. Covariant figure of deviation value of $\mathrm{La}$-ash index in the $\mathrm{C} 2$ coal seam. The deviation value of $\mathrm{La}$ refers to Table 4 , and the ash index refers to Table 3.

can be used as the indicator to identify different evolutionary processes of magma ${ }^{9,15}$. The ratio of $\mathrm{Sr} / \mathrm{Ba}$ increases with the distance away from the coast and can qualitatively reflect paleosalinity; specifically, the ratio of $\mathrm{Sr} / \mathrm{Ba}<1$ in freshwater sediments, $>1$ in marine sediments, and between 0.6 and 1 in blackish water facies ${ }^{16}$. The ash index $\left(\mathrm{SiO}_{2}+\mathrm{Al}_{2} \mathrm{O}_{3}\right) /\left(\mathrm{MgO}+\mathrm{CaO}+\mathrm{Fe}_{2} \mathrm{O}_{3}\right)$ mainly reflects the degree of reduction for a peat bog. When it is high, the reduction of media is weak in peat precipitation, and the aqueous nature of freshwater is evident; when it is low, the reduction of media is strong in peat precipitation ${ }^{17}$.

Based on the covariant figure of "deviation values" of lanthanides and some of the above elements' ratios, the 12 continuously metamorphous coal samples in the $\mathrm{C} 2$ coal seam of Handan can be divided into two different series. For instance, based on the covariant figure of the deviation value of the La-ash index in Fig. 5, these continuously metamorphous coal samples can be divided into series A (No. 1-No. 7), and series B (No. 8-No. 12). The literature ${ }^{10}$ indicates that samples No. 1-No. 7, from the coal seam are uninfluenced or slightly influenced by magmatic-hydrothermal fluids in C2, whereas samples No. 8-No. 12, from the coal seam are strongly influenced by magmatic-hydrothermal fluids in $\mathrm{C} 2$. The deviation values of $\mathrm{La}$ or $\mathrm{Lu}$ vs. the ash index can also constitute a similar covariant figure. Moreover, based on the covariant figure of the goodness of fit of chondrite-linear lanthanides and the ash index, these continuously metamorphous coal samples can also be divided into series A and series B. This suggests that the "deviation value" and goodness of fit are both useful "individual parameters" or "states parameters" that can indicate indicating their geochemical environments. Some "parameters in common", such as the mentioned slope value (regression coefficient) of chondrite-linear lanthanides, power value after power function regression, and exponential value after exponent function regression, can all be used to distinguish the two series of A and B in the C2 coal seam in the covariant figure plotted from the "parameters in common" and ash index. Therefore, these "parameters in common" in fact fall within the scope of "two-sided parameters" described above. Other "parameters in common" observed by the predecessors, such as $\delta \mathrm{Eu}, \mathrm{can}$ also constitute a good covariant figure capable of identifying geological environments (Fig. 6). In Fig. 6, the samples of A series in the C2 coal seam, being uninfluenced or slightly influenced by magmatic-hydrothermal 


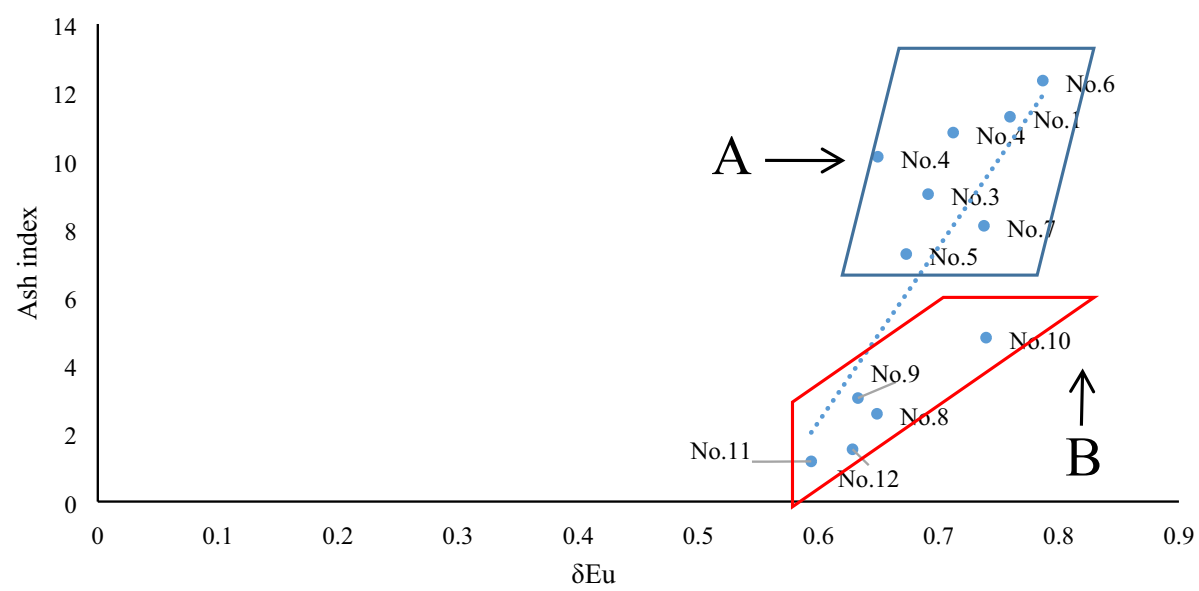

Figure 6. Covariant figure of $\delta \mathrm{Eu}$-ash index in the $\mathrm{C} 2$ coal seam. The value of $\delta \mathrm{Eu}$ refers to Table 1 , and the ash index refers to Table 3.

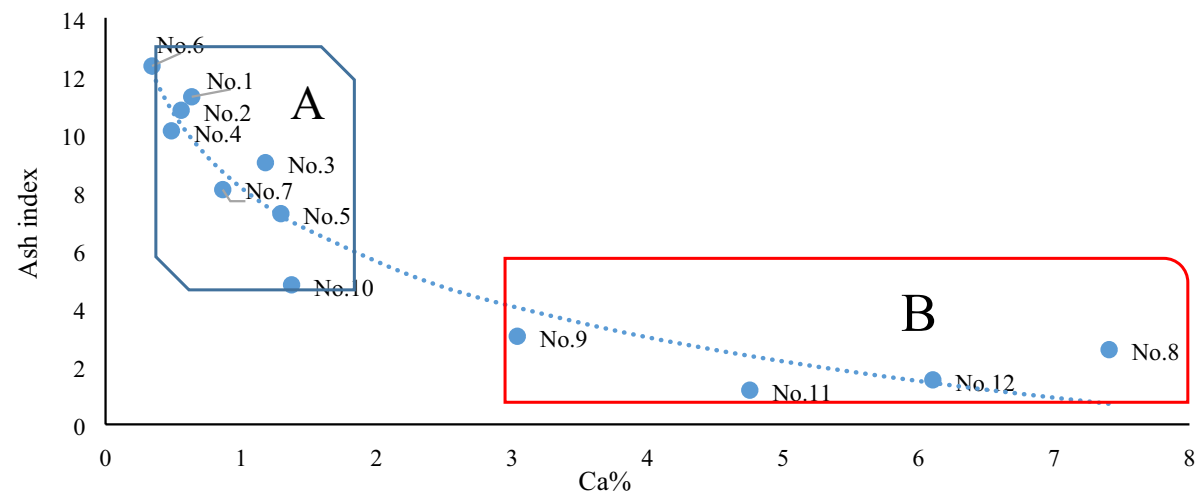

Figure 7. Covariant figure of $\mathrm{Ca}-\mathrm{ash}$ index in the $\mathrm{C} 2$ coal seam. The concentration of $\mathrm{Ca}$ and the ash index refer to Table 3.

fluids are basically above the regression line, whereas those of B series in the C2 coal seam strongly influenced by magmatic-hydrothermal fluids are all below the regression line. Even the covariant figure constituted by $\Sigma$ REE, ILREE, LREE/HREE, and the ash index can be used to distinguish A and B in the C2 coal seam. This result can also be inferred from the formulas (1) and (2).

The sixteen elements of $\mathrm{B}, \mathrm{F}, \mathrm{Cl}, \mathrm{Br}, \mathrm{Hg}, \mathrm{As}, \mathrm{Co}, \mathrm{Cu}, \mathrm{Ni}, \mathrm{Pb}, \mathrm{Sr}, \mathrm{Mg}, \mathrm{Ca}, \mathrm{Mn}, \mathrm{Zn}$, and $\mathrm{U}$ in Table 3 and the ratios with certain geological or geochemical environmental significance (such as $\mathrm{Sr} / \mathrm{Ba}, \mathrm{Th} / \mathrm{U}$, and $\mathrm{Th} / \mathrm{Co}$ ), as well as other element ratios (such as $\mathrm{Nb} / \mathrm{Ta}$ ), can constitute a covariant figure capable of indicating a geological environment or origin through the "deviation values" of lanthanides or ash indexes. The above elements can be found within the hydrothermal fluid of magma ${ }^{10}$. For instance, the covariant figure of $\mathrm{Ca} \%$ - ash index can reflect a strong logarithmic negative correlation between the indexes but also clearly distinguish between $\mathrm{A}$ and $\mathrm{B}$ of the $\mathrm{C} 2$ coal seam (Fig. 7). Certain covariant figures can also reflect slight differences in environmental influence. For example, although the covariant figure of the Lu deviation value-Co can clearly distinguish between A and B, it fails to classify sample No. 8, which is also strongly influenced by the hydrothermal fluids of magma, into Series B. According to a previous study (Figures 10 and 11, see reference) ${ }^{10}$, although some transition elements such as Co are found in the hydrothermal fluids of magma, in the phase of sample No. 8, the hydrothermalism is not strong enough. Herein, compared to the samples prior to No. 7, which are uninfluenced or slightly influenced by hydrothermal fluids of magma, there are few changes in elements, such as Co. Thus, sample No. 8 is not separated from Series A (Fig. 8).

Environmental indication significance of parameter $\boldsymbol{R}_{\max } \cdot R_{\max }$, an important parameter used to characterize the metamorphic degrees of coal in the Handan C2 coal seam in Hebei, has no evident correlation with any parameter of the geochemical effect equation for lanthanides. However, the covariant figure constituted by $R_{\max }$ with other parameters still has certain environmental significance. For example, the covariant figure of the $R_{\max }$-ash index reflects the significant negative correlation between the $R_{\max }$ and ash index while clearly distinguishing between A and B for the C2 coal seam (Fig. 9). In turn, this completely indicates several supermetamorphic coal forms in the $\mathrm{C} 2$ coal seam with the superposition of the magmatic-hydrothermal process in 


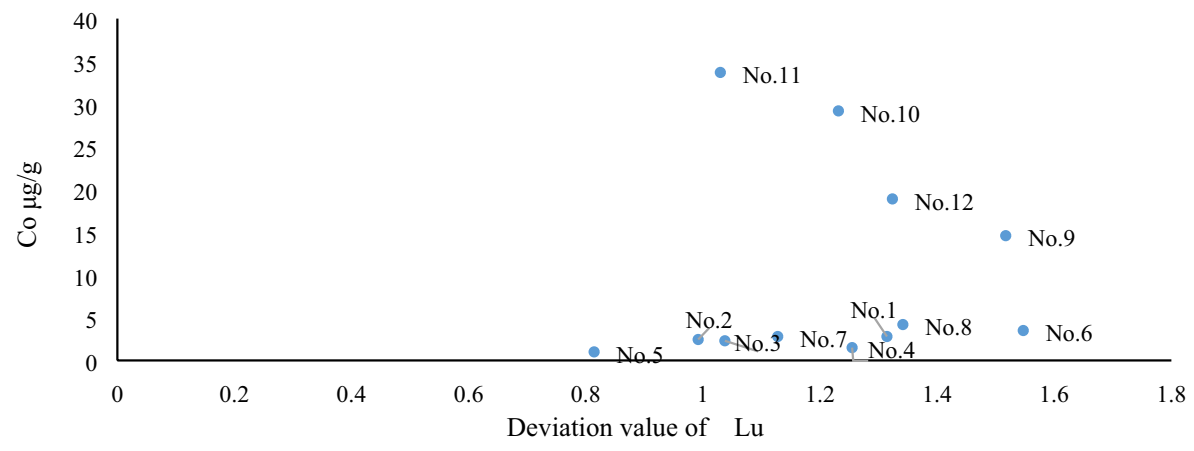

Figure 8. Covariant figure of the deviation value of $\mathrm{Lu}-\mathrm{Co}$ in the $\mathrm{C} 2$ coal seam. The deviation value of Lu refers to Table 4, and the concentration of Co refers to Table 3.

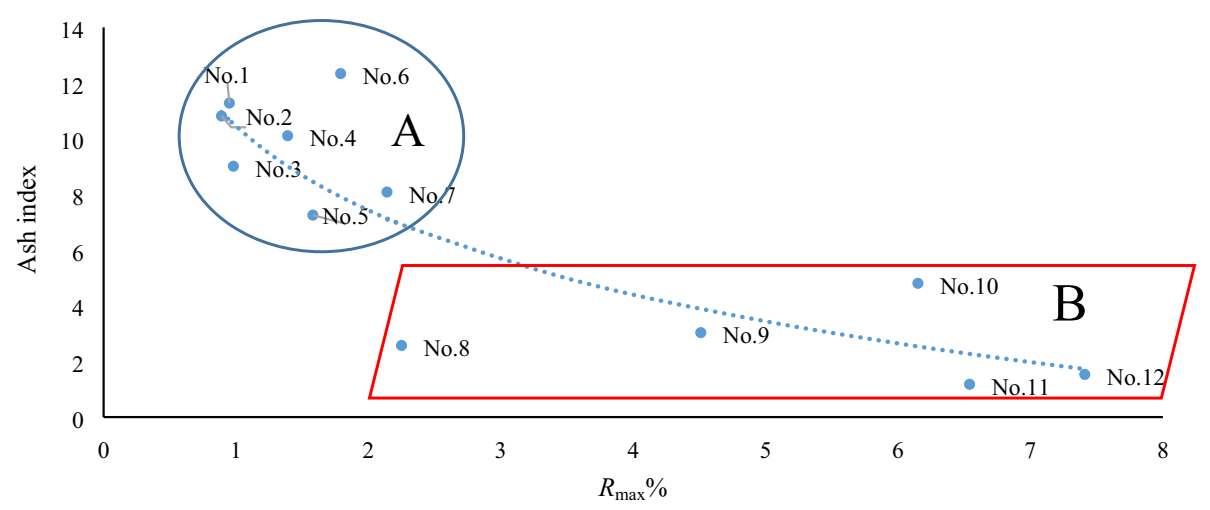

Figure 9. Covariant figure of $R_{\max }$-ash index in the $\mathrm{C} 2$ coal seam. The value of $R_{\max }$ refers to Table 1 , and the ash index refers to Table 3.

Yanshanian based on plutonic metamorphism. For series A of samples No. 1-No. 7, the ash index reflects the changes in the reduction degree of peat bog upon the formation of $\mathrm{C} 2$ coal seam ${ }^{17}$. However, series $\mathrm{B}$ of samples No. 8-No. 12, it is more likely to reflect the result of magmatic-hydrothermal influence on the coal seam. Specifically, the large-scale injection of $\mathrm{Ca}$ and $\mathrm{Mg}$ in the hydrotherm causes the ash index of the coal seam to present an overall declining trend. The same applies to the covariant figures constituted by the above elements or elements' ratios related to magma hydrothermal fluid with the ash index or some parameters of the geochemical effect of lanthanides. Similarly, the covariant figure of $R_{\max }-\mathrm{Th} / \mathrm{U}$ and $R_{\max }-\mathrm{Th} / \mathrm{Co}$ can reflect the power function negative correlation between them and clearly distinguish between A and B for the $\mathrm{C} 2$ coal seam. Moreover, although $R_{\max }$ has no correlation with $\mathrm{Sr} / \mathrm{Ba}$, it can clearly distinguish between these two series as well.

\section{Conclusions}

1. The geochemical significance of the parameters in the geochemical effect regression equation for lanthanides was systematically explained, and new descriptive formulas characterizing the geochemical behaviors of lanthanides were proposed. We speculate that different geochemical processes of lanthanides can be described with different regression functions; the higher the goodness of fit, the purer and more singular the different geochemical behaviors or processes of lanthanides will be.

2. Based on the above speculation, the concept of lanthanide deviation was proposed, and the parameters in the geochemical effect regression equation for lanthanides were roughly divided into three types: The first type is parameters acting in common, and its geochemical significance fits within any geochemical process experienced by any geological body other than coal. The second type is individual or state parameters, which are probably only applicable to certain geological bodies or geochemical environment that have stronger geochemical, environmental, and genetic significances. However, the difference between individual parameters and parameters in common is not "either this or that". In this study, some parameters acted in common, such as the regression coefficients of some functions. Moreover, they had environmental indication significance under certain conditions. Therefore, the concept of "two-sided parameters" was established.

3. In this study, lanthanides had certain interactions with the elements from magmatic fluid or certain nonmagmatic-hydrothermal-sourced elements such as $\mathrm{Al}$ and $\mathrm{Si}$. Although the sources and changes of $\sum \mathrm{REE}$ and $\sum$ LREE are not related with the magmatic-hydrothermal effect, they have certain interactions with the 
elements from the magmatic hydrothermal fluid. This manifests that the covariant figure with these elements can also be used to indicate different metamorphic series in the $\mathrm{C} 2$ coal seam. Moreover, this covariant figure conforms to the scientific logic inside regression formulas proposed in this study.

4. $R_{\max }$ in the $\mathrm{C} 2$ coal seam of Handan reflected the metamorphic degree of coal and indicated the influence of post-modification activities to coal through the combination with other indexes. For example, in the covariant figure of $R_{\max }$ and $\mathrm{Sr} / \mathrm{Ba}$ or the ash index, the degree of the influence of later magmatic-hydrothermal fluid on the $\mathrm{C} 2$ coal seam was clearly reflected.

\section{Data availability}

All the data including raw and processed data are available within the paper and Appendix.

Received: 21 February 2020; Accepted: 16 June 2020

Published online: 10 August 2020

\section{References}

1. Yang, J. Y. Effect on coal-geochemistry of lanthanide elements-an example of middle rank coal from Weibei. J. Chin. Rare Earth Soc. 26, 486-490 (2008) (in Chinese with English abstract).

2. Yang, J. Y. Special appearance of REE geochemistry of soluble hydrocarbon in coal-an example of a middle rank coal from Weibei. J. Fuel Chem. Technol. 37, 527-532 (2009) (in Chinese with English abstract).

3. Yang, J. Y. The organic or inorganic affinity of lanthanide elements in coal and its evolution-a case study of the Late Paleozoic 5\# coal from Weibei. J. China Univ. Min. Technol. 39, 402-407 (2010) (in Chinese with English abstract).

4. Yang, J. Y. The effect on geochemistry of the rare earth element: an example of important application in the REE classification for petrology and study for migrating of the REE during the burning of lignite. J. Hunan Univ. Sci. Technol. (Nat. Sci. Ed.) 26, 113-118 (2011) (in Chinese with English abstract).

5. Yang, J. Y. Geochemistry of lanthanides in late Paleozoic coal from Weibei. J. Fuel Chem. Technol. 39, 887-892 (2011) (in Chinese with English abstract).

6. Yang, J. Y., Zhao, L. \& Zhang, W. G. The geochemical effect of Lanthanides: Its types and application for magmatic rocks-a new method to semi-quantitatively determine strength of magmatic fluid complexation and fractional crystallization. J. Earth Sci. 25, 252-262 (2014).

7. Yang, J. Y. Relationship between lanthanides and organic matter in coal from FTIR analysis results: an example of No. 8 seams from Taiyuan Xishan Mine, North China. J. China Coal Soc. 40, 1109-1116 (2015) (in Chinese with English abstract).

8. Yang, J. Y. Regression equation of geochemical effect of lanthanide and preliminary study on scientific significance of its parameters: an example of different types from No. 8 coal seam, Shanxi Province, China. J. China Coal Soc. 44, 2197-2205 (2019) (in Chinese with English abstract).

9. Liu, Y. J. \& Cao, L. M. Introduction to Elemental Geochemistry (Geol. Publ House, Beijing, 1987) (in Chinese).

10. Dai, S. F. \& Ren, D. Y. Effect of magmatic intrusion on mineralogy and geochemistry of coals from the Fengfeng-Handan coalfield, Hebei, China. Energy Fuel 21, 1663-1673 (2007).

11. Seredin, V. V. Metalliferous Coals: Formation Conditions and Outlooks for Development Coal Resources of Russia, VI 452-519 (Geoinformmark, Moscow, 2004) (in Russian).

12. Jenner, F. E. \& O'Neill, H. S. C. Analysis of 60 elements in 616 ocean floor basaltic glasses. Geochem. Geophys. Geosyst. 13, 1-11 (2012).

13. Yang, J. Y., Zhang, W. G. \& Qu, L. Y. Preliminary study on the acid removal rate of element in the different rank of coal. J. China Coal Soc. 43, 519-528 (2018) (in Chinese with English abstract).

14. Dai, S. F. et al. Mineralogical and geochemical anomalies of late Permian coals from the Fusui Coalfield, Guangxi Province, southern China: Influences of terrigenous materials and hydrothermal fluids. Int. J. Coal Geol. 105, 60-84 (2013).

15. Tu, G. Z. et al. In Dispersed Element Geochemistry and Metallogenic Mechanism (eds Wang, Z. J. \& Qi, X. L.) (Geol. Publ. House, Beijing, 2004) (in Chinese).

16. Wang, A. H. Discriminant effect of sedimentary environment by the $\mathrm{Sr} / \mathrm{Ba}$ ratio of different existing forms. Acta Sedimentol. Sin. 14, 168-173 (1996) (in Chinese with English abstract).

17. Zhao, S. Q. In Practical Coal Petrology (ed. Mou, X. X.) (Geol. Publ. House, Beijing, 1991) (in Chinese).

\section{Acknowledgements}

Special thanks are given to editor and reviewers for their careful reviews. The wonderful scientific data from the article of Prof. Shifeng Dai are highly appreciated. We gratefully acknowledge financial support from the National Natural Science Foundation of China (Nos. 41672145 and 41472133), and the Science Foundation of Hebei (No. D2018402093).

\section{Author contributions}

J.Y.Y. proposed the main idea and procedure of the research. J.Y.Y., and S.J.Q. performed the data analysis and drafted the manuscript, and J.L. and F.X. helped to the computational process. All of the authors read and approved the final manuscript.

\section{Competing interests}

The authors declare no competing interests.

\section{Additional information}

Supplementary information is available for this paper at https://doi.org/10.1038/s41598-020-70477-1.

Correspondence and requests for materials should be addressed to J.Y. or S.Q.

Reprints and permissions information is available at www.nature.com/reprints.

Publisher's note Springer Nature remains neutral with regard to jurisdictional claims in published maps and institutional affiliations. 
(c) (i) Open Access This article is licensed under a Creative Commons Attribution 4.0 International cc) License, which permits use, sharing, adaptation, distribution and reproduction in any medium or format, as long as you give appropriate credit to the original author(s) and the source, provide a link to the Creative Commons license, and indicate if changes were made. The images or other third party material in this article are included in the article's Creative Commons license, unless indicated otherwise in a credit line to the material. If material is not included in the article's Creative Commons license and your intended use is not permitted by statutory regulation or exceeds the permitted use, you will need to obtain permission directly from the copyright holder. To view a copy of this license, visit http://creativecommons.org/licenses/by/4.0/.

(C) The Author(s) 2020 